Article

\title{
Innovative Design and Fuzzy Logic Control for An Underground Moving Sieve Jig
}

\author{
Deyong Shang ${ }^{1,2, *} \mathbb{C}$, Zhiyuan Yang ${ }^{1, *}$, Junjie Wang ${ }^{1}$, Yuwei Wang ${ }^{1}\left(\mathbb{D}\right.$ and Yue Liu ${ }^{3,4}(\mathbb{D}$ \\ 1 School of Mechanical Electronic and Information Engineering, China University of Mining and Technology (Beijing), \\ Beijing 100083, China; egn_wang@163.com (J.W.); wangyuwei@student.cumtb.edu.cn (Y.W.) \\ 2 Institute of Smart Mines and Robotics, China University of Mining and Technology (Beijing), \\ Beijing 100083, China \\ 3 Department of Mechanical Engineering, Tsinghua University, Beijing 100084, China; \\ liuy2018@tsinghua.org.cn \\ 4 Mechanical Electrical Engineering School, Beijing Information Science \& Technology University, \\ Beijing 100084, China \\ * Correspondence: shangdeyong@cumtb.edu.cn (D.S.); yangzhiyuan@student.cumtb.edu.cn (Z.Y.); \\ Tel.: +86-188-1072-3065 (Z.Y.)
}

Received: 9 November 2020; Accepted: 29 November 2020; Published: 3 December 2020

\begin{abstract}
Underground gangue filling technology in coal mines is one of the effective ways to realize green mining. In this paper, a process of underground raw coal primary selection is proposed, which is based on a mechanical sieve jig as the main washing equipment. It refers to the structure of the ground mechanical moving sieve jig. It optimizes and improves the main structure of the jig machine's driving mechanism and gangue discharge mechanism. It meets the requirements of the technology and the narrow space environment in the underground mine and realizes the effective separation of coal and gangue. In the jigging process of a moving sieve, it is very important to keep the jig bed stable and precisely control the quantity of gangue discharge for improving the system separation accuracy and efficiency. In this paper, a control method based on a fuzzy logic combination is proposed to realize the fuzzy logic control of the motor speed of gangue discharging, which aims at the nonlinear, time-varying uncertainty and pure lag characteristics of the control system of the underground moving sieve jig. Further industrial experiments were carried out and we obtained the variation law of the gangue's quality in the moving sieve and the output curve of the gangue motor frequency under three working conditions. The experimental results show that the fuzzy logic control algorithm can quickly stabilize the jig bed in the vibrating sieve when the quantity of gangue changes abruptly or fluctuates greatly. It improves the separation efficiency of coal and gangue and effectively solves the problems of nonlinearity, time-varying and hysteresis in the control process of the moving sieve jig.
\end{abstract}

Keywords: coal gangue; jig; underground; logic control; fuzzy control

\section{Introduction}

In the traditional coal production model, coal mining and coal preparation are independent systems. Coal gangue is a solid waste generated during coal mining and coal washing. On the one hand, it increases the cost of coal per ton and occupies the lifting transportation capacity. On the other hand, there is a variety of metal and non-metal elements and a small amount of heavy metal elements in gangue, which can cause serious environmental pollution when piled on the ground [1]. The new mode of green coal production with integrated mining and dressing combines coal mining technology, coal preparation technology and filling technology to achieve the goal of high efficiency, green and 
zero emissions of coal mining [2-5]. This technology can not only reduce the discharge of coal gangue and eliminate the pollution of the gangue hill into the environment, but also solve the problem of large-scale ground collapse caused by the collapse of the mining area.

At present, there is limited research on underground coal preparation technology and equipment at home and abroad [6-9]. The moving sieve jigging gangue discharge method has a simple configuration, convenient maintenance and low cost, which can meet the needs of underground gangue discharge in coal mines. However, due to the limitation of underground operation space, equipment layout and other factors in coal mines, it is impossible to directly apply the jigging machine to the underground in accordance with the ground gangue discharge method, which requires the structural optimization of the jig machine to achieve a similar effect on the ground. The KHD company (KHD HUMBOLDT-WEDAG $\mathrm{GmbH}$ ) proposed the idea of using a moving sieve jig machine to wash coal and discharge gangue in the mine [10]. Zheng and Wang [11,12] tried to use vision or laser recognition sorting systems to study the separation of coal and gangue.

Jigging coal preparation is a very complex dynamic process of liquid-solid interaction [13,14]. Due to the complex stratification mechanism of coal gangue and the multivariate interactions, it is difficult to describe the relationship between production operations and control objectives with traditional mathematical models. Mukherjee, A.K used a PID (Proportional Integral Derivative) regulator to control the discharge of the jigger through the ash content of the gangue [15,16]. Kumar [17] analyzed the performance of a jig for coal cleaning using 3D response surface methodology. G. J.S [18] proposed a jig control scheme with a variable waveform. Zhu [19] proposed the use of an artificial neural network to learn the mapping relationship between jigger operating factors and sorting indicators. $\mathrm{Ma}$ [20] proposed an intelligent control system that took clean coal ash and clean coal recovery as the control targets. Ni [21] proposed an online control system for jigging clean coal ash based on fuzzy control theory and methods. Yang [22] carried out research on the jig bed state recognition method.

The coal washing system of the moving sieve jig has the characteristics of high nonlinearity, time-varying uncertainty and pure hysteresis so a single control method can no longer meet the requirements [23] and the combination of multiple control methods has become an efficient control method. In order to improve the stability and efficiency of the underground sorting system, this paper proposes a control method based on fuzzy logic, which comprehensively considers the thickness of the jig bed and the frequency of waste discharge and it effectively solves the problem of unstable gangue discharge of the underground mechanical moving sieve jig.

\section{Process Design of an Underground Coal Primary Selection System}

The underground raw coal primary selection system uses mechanical moving sieve jigs as the main washing equipment. It is mainly composed of raw coal screening, lump coal washing, crushing and transportation and a slime water circulation treatment. The process is shown in Figure 1. The lump coal is transported to the roller screen for classification after removing the ferromagnetic impurities mixed in the raw coal by a belt reloading separator. Screened according to the preset particle size, the mixed coal with a small particle size under the screen returns to the raw coal belt or directly into the coal bunker and the mixed coal with a large particle size on the screen enters the underground moving sieve jig machine for washing. The raw coal sorted by the moving sieve jig is divided into two types. The sieved lump clean coal and the screened material are transported to the raw coal transportation belt together and the screen gangue enters the gangue storage or discharge system. The technical terms together with their function are given in Appendix A. 


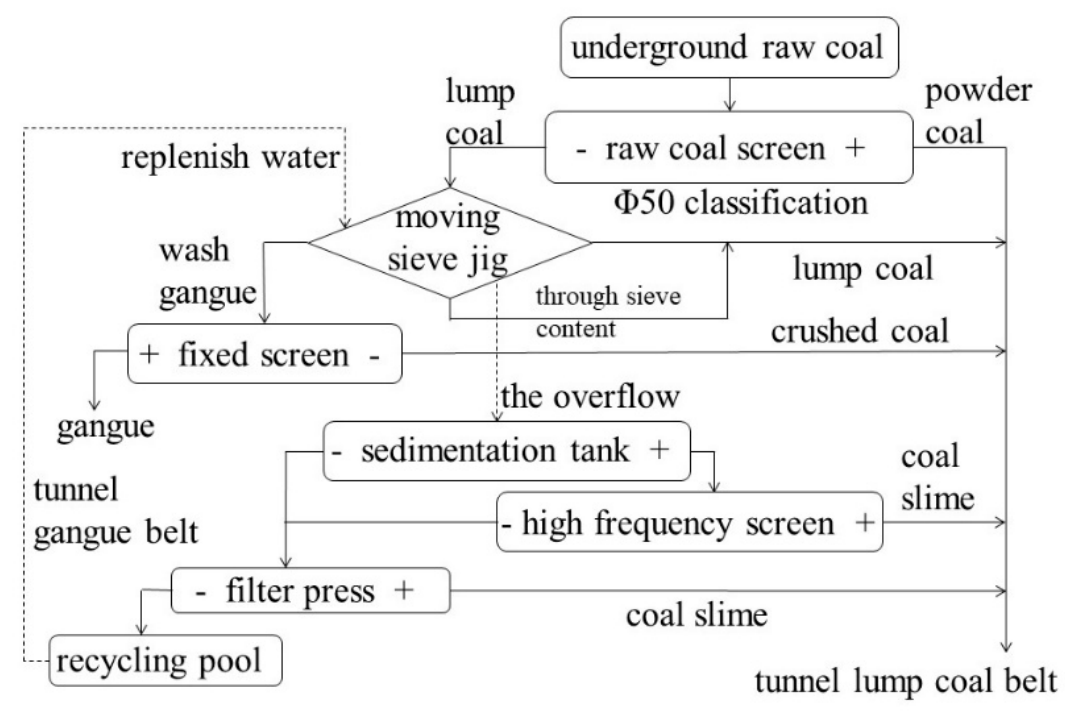

Figure 1. The typical process flow of a raw coal preparation system.

\section{Innovative Design of an Underground Jigging Machine Structure}

The driving mechanism of a ground mechanical jig is shown in Figure 2. The transmission mechanism such as the motor, reduction mechanism and crank connecting rod were assembled on an independent base. This structure was difficult to guarantee various dimensional errors during installation and the vibration of the base aggravates the wear of the equipment. After optimization and transformation, the independent foundation was cancelled and the main driving mechanism was directly installed on the box body. It was conducive to the mine roadway design and construction and reduced the position error of the main drive shaft. In addition, the center of gravity of the drive system was located within the box body and the positioning of the shaft and the bearing seat was more accurate when installing, which was more stable than the traditional layout and also reduced noise and vibration. The no-load power of the main drive motor was reduced from $20-25 \mathrm{~kW}$ during no-load operation on the ground to $15 \mathrm{~kW}$. The main drive mechanism is shown in Figure 3.

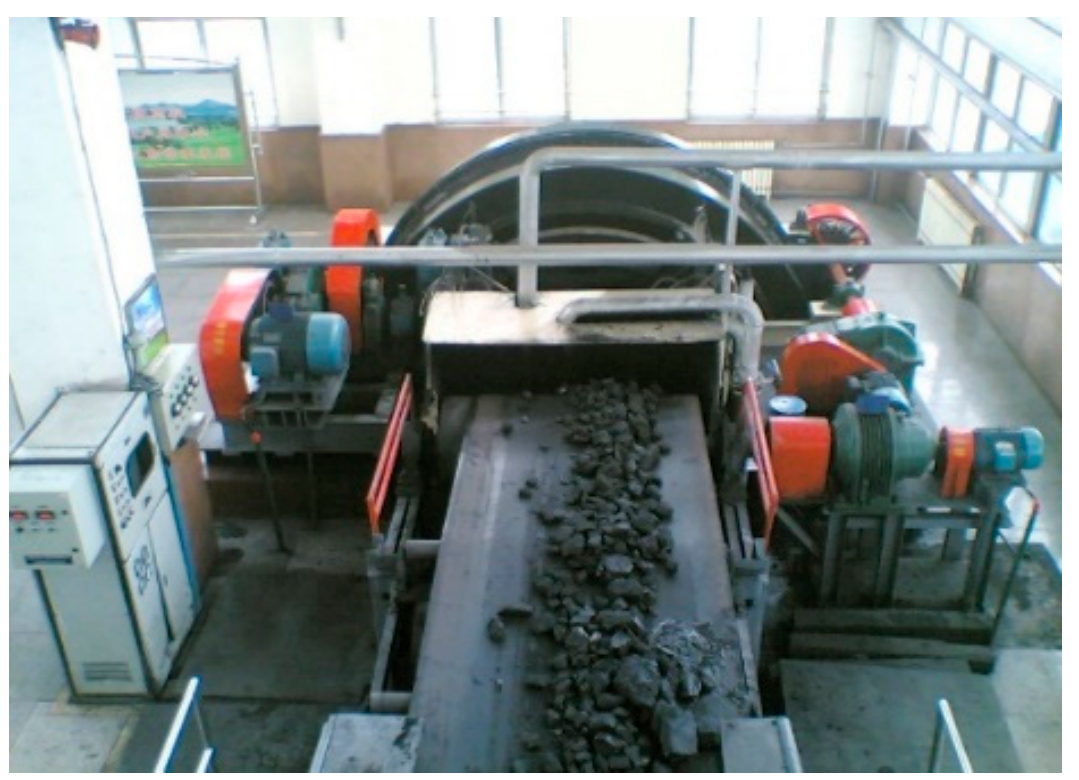

Figure 2. The normal ground mechanical jig. 


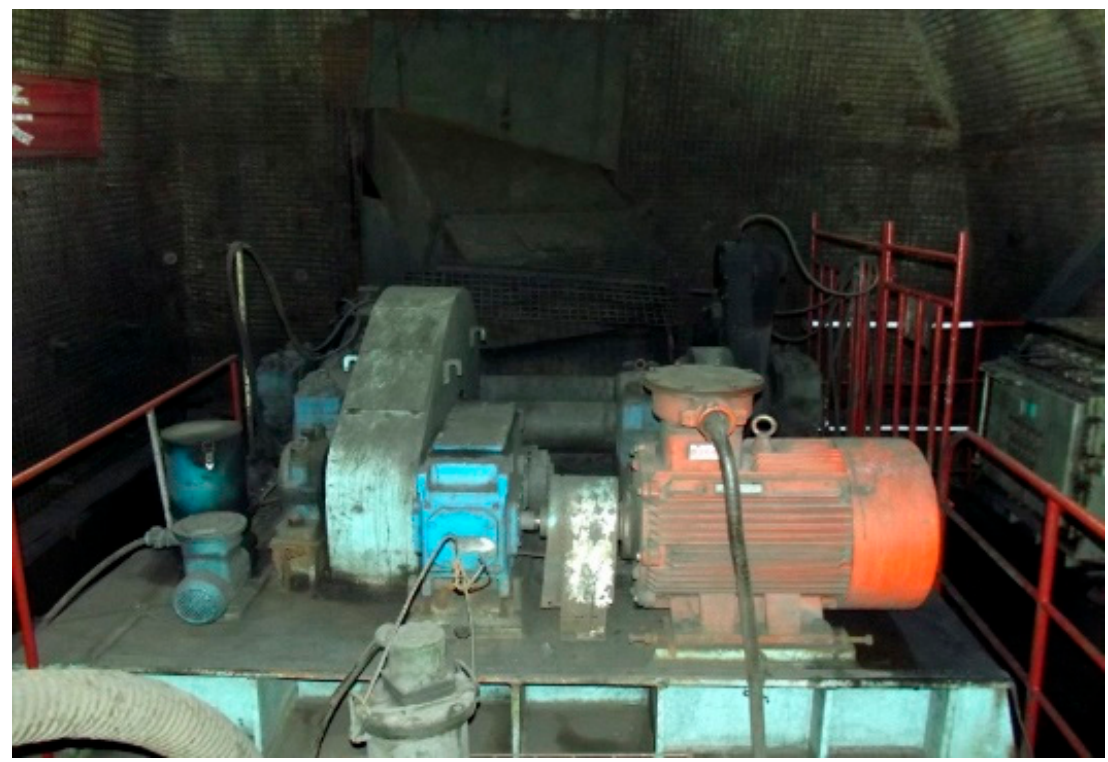

Figure 3. The new driving system of the underground mechanical moving sieve jig.

In order to solve the problem of easy blockage by large gangue, the design increased the size of the gangue outlet and improved the gangue handling capacity. At the same time, two parallel scrapers were designed to lift the separated coal and gangue to the water surface. This solution was simpler and more reliable than the screw mechanism discharging method adopted by the KHD company in Germany. The structure of the underground mechanical moving sieve jig is shown in Figure 4, which was mainly composed of a combined box body, a moving sieve, a driving mechanism, a gangue discharging mechanism, a scraper and an electric control system.

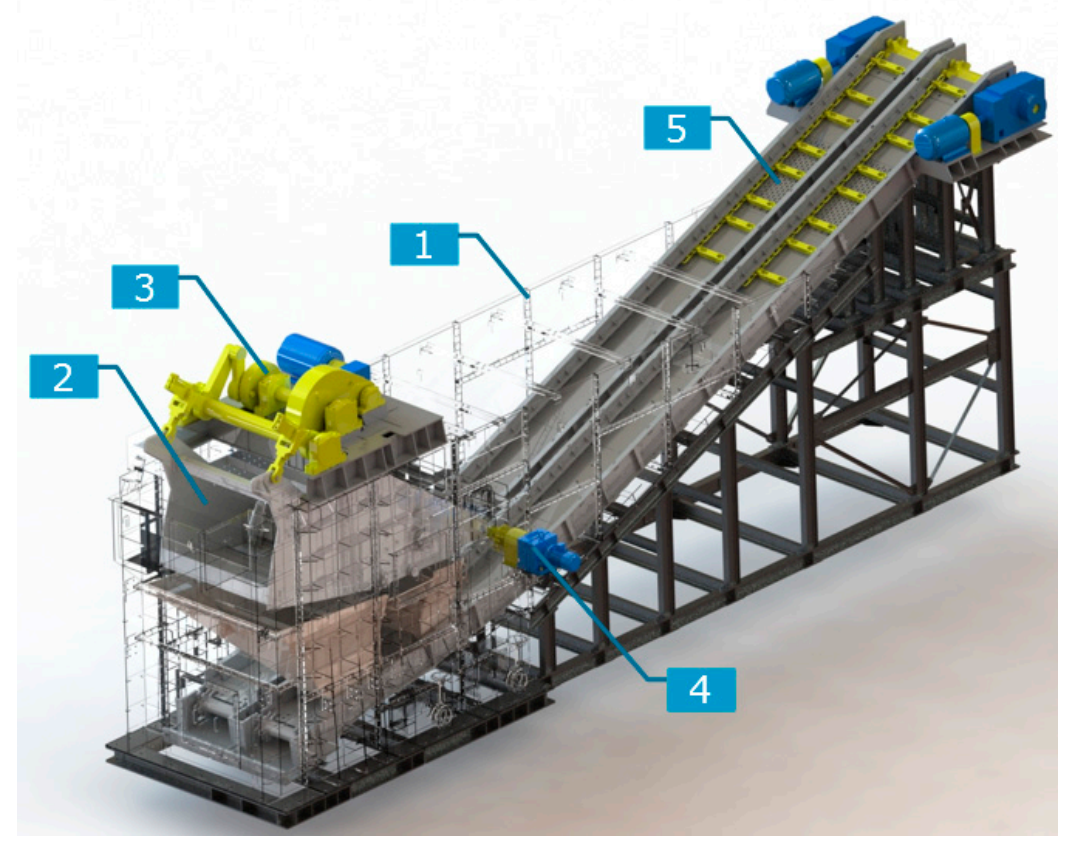

Figure 4. The structure of the jigger. (1): combined box body. (2): moving sieve. (3): driving mechanism. (4): gangue discharging mechanism. (5): scraper lifting mechanism. 


\section{Fuzzy Logic Control Design of Jig}

\subsection{Principle of Logical Linear Control}

Maintaining the stability of the jig bed plays an important role in improving the separation effect of coal gangue. However, the production of raw coal underground is not stable. Without the cooperation of the buffer bin and the feeder, the change of coal gangue feeding quantity has a great influence on the impact of the jig bed formed by the moving sieve. It is necessary to automatically adjust the speed of the gangue wheel according to the change of the raw coal input to ensure the stability of the jig bed. The output power of the main drive motor of the moving sieve body changes can indirectly reflect the change of the sieve body feed volume. This variable can be processed to control the frequency converter of the gangue wheel drive motor so as to continuously and automatically control the speed of the gangue wheel.

According to the requirements of the moving sieve for the gangue discharge motor, the behavior of the driving motor under certain circumstances is that when the thickness of the gangue layer is lower than the height of the gangue outlet, the rotation speed of the gangue wheel motor is zero. When the thickness of the gangue layer exceeds the height of the gangue outlet, the gangue wheel motor is started and as the thickness of the gangue layer increases, the speed of the gangue wheel motor speeds up. When the thickness of the gangue layer reaches the upper edge of the baffle, the speed of the gangue wheel is the fastest. The working characteristic curve of the moving sieve motor is $O A-A B-B C-C D$, as shown in Figure 5. When the power of the moving sieve motor is lower than $P_{1}$, the motor speed is 0 ; that is, no gangue is discharged in the OA section. When the power of the moving sieve motor is between $P_{1}$ and $P_{\mathrm{t}}$, the motor runs in the BC section. At this time, the output frequency of the inverter changes between 5 and $50 \mathrm{~Hz}$. When the power of the moving sieve motor is $P_{\mathrm{t}}$, the corresponding inverter output frequency is $f_{\mathrm{t}}$ and the motor runs at point $\mathrm{M}$. When the power of the moving sieve motor exceeds $P_{\mathrm{h}}$, it runs in the CD section and the inverter output is $50 \mathrm{~Hz}$ and the moving sieve motor runs at full speed.

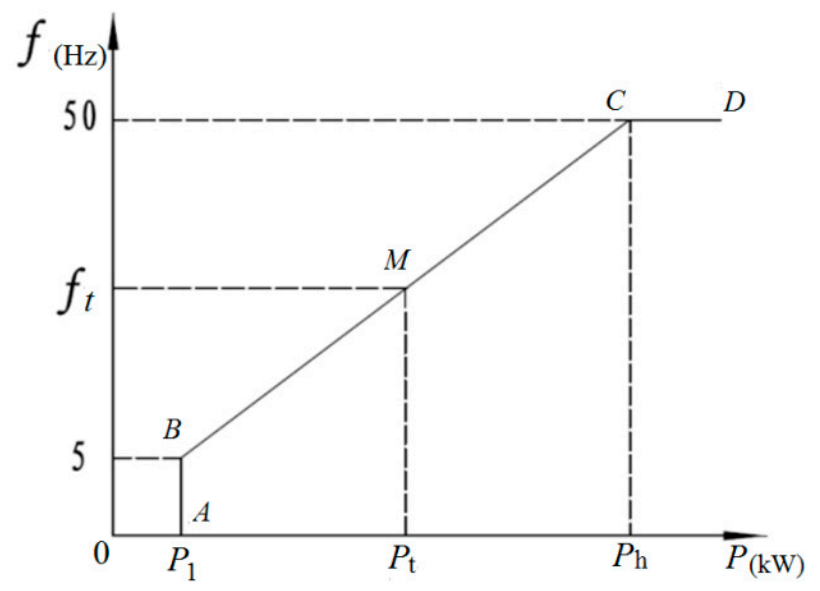

Figure 5. The working characteristic curve of a gangue motor.

The logical linear formula of motor frequency is obtained as follows:

$$
f_{\mathrm{t}}=\frac{45}{P_{\mathrm{h}}-P_{\mathrm{t}}}+\frac{5 P_{\mathrm{h}}-50 P_{1}}{P_{\mathrm{h}}-P_{1}} .
$$

In the formula, $P_{\mathrm{t}}$ is the real-time power of the moving sieve motor, $\mathrm{kW} ; P_{\mathrm{h}}$ is the upper limit of the moving sieve motor, $\mathrm{kW}$ (can be set on site); $P_{1}$ is the lower limit of the moving sieve motor, $\mathrm{kW}$ (can be set on site) and $\mathrm{f}_{\mathrm{t}}$ is the real-time frequency of the gangue discharging motor during normal operation, Hz. 


\subsection{Fuzzy Control Design}

(1) Fuzzification

Fuzzy logic summarizes the control experience of domain experts and skilled operators into a set of conditional sentences of qualitative description and uses fuzzy set theory for reasoning so that the controller can accept human experience and imitate human operation strategies for control. There are two kinds of fuzzy inference algorithms, the Mamdani-type and the Sugeno-type fuzzy logic controller. The Mamdani-type algorithm takes fuzzy language as the rule conclusion while the Sugeno-type algorithm takes the linear function of the input of the rule premises as the rule conclusion. It has several advantages such as the strong robustness and excellent characteristics for the nonlinear, time-varying and time-delay systems that are difficult to solve by conventional control [24-29]. The structure of the fuzzy controller system is shown in Figure 6. In this paper, we chose PLC (Programmable Logic Controller) as the fuzzy controller. The input was the power deviation $e$ and the deviation change rate $\Delta e$ of the moving sieve and the system output was the gangue frequency curve slope correction amount $u$. The principle of the fuzzy control system is shown in Figure 7.

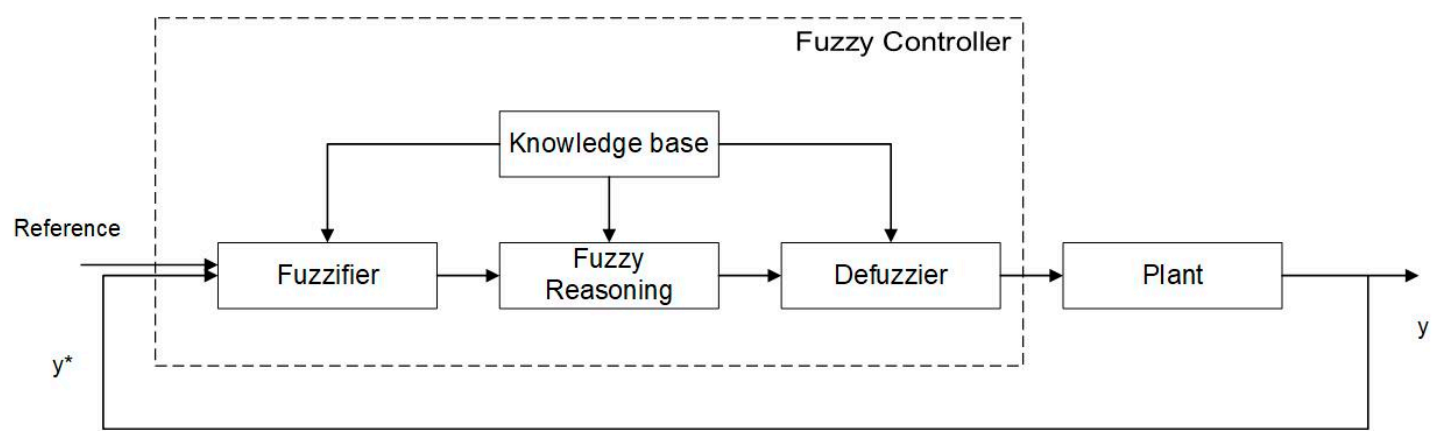

Figure 6. The structure of the fuzzy controller.

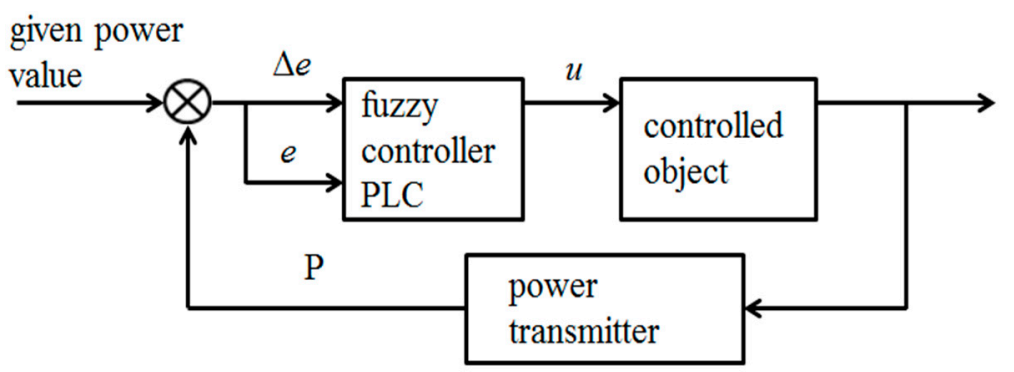

Figure 7. The schematic diagram of the fuzzy control system.

The language variables, basic domain, fuzzy subset and fuzzy domain are shown in Table 1.

Table 1. Fuzzy Control Parameter Table.

\begin{tabular}{cccc}
\hline Variable & $\boldsymbol{e}$ & $\boldsymbol{\Delta} \boldsymbol{e}$ & $\boldsymbol{u}$ \\
\hline Language variables & $E$ & $\Delta E$ & $U$ \\
Basic domain & $\{-20,20\}$ & $\{-3,3\}$ & $\{0.5,1.5\}$ \\
Fuzzy subset & NB, NM, NS, ZO, PS, PM, PB \\
Fuzzy domain & $\mathrm{A}=\{-3,3\}$ & $\mathrm{B}=\{-3,3\}$ & $\mathrm{C}=\{-3,3\}$ \\
\hline
\end{tabular}

We can discretize the three variables according to Formula (2):

$$
y=\left[\frac{2 n}{b-a}\left(x-\frac{a+b}{2}\right)\right] .
$$


In the formula, $x \in[a, b], a$ and $b$ are the maximum and minimum values in the basic universe and $n$ is the dispersion, $n=7$.

We then selected the membership function of each variable as a triangular function and then made the membership function of each variable according to Table 1, as shown in Figure 8.

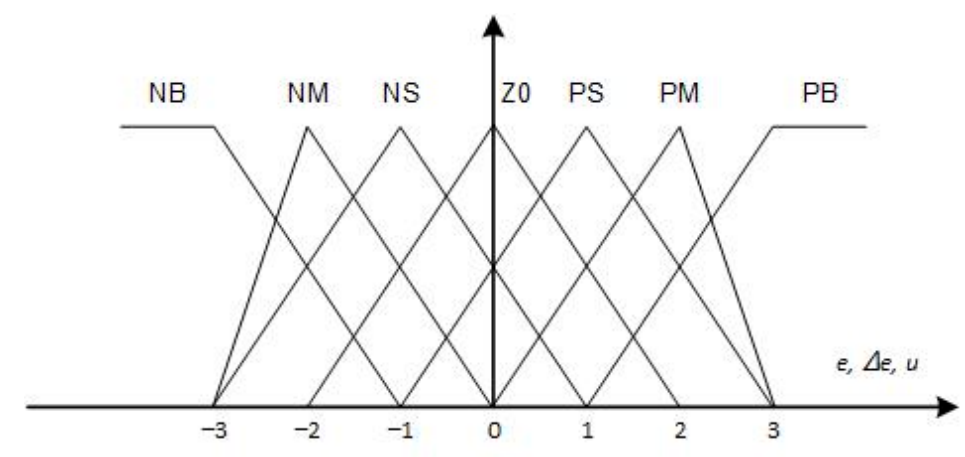

Figure 8. The membership function of the variable.

(2) Fuzzy Rules

According to the control requirements of the system technology combined with actual control experience, the fuzzy control rule table formed is shown in Table 2. The control rules are "if $E$ is $E_{i}$ and $\Delta E$ is $\Delta E_{i}$, then $U$ is $U_{i}, i=1,2, \ldots, 7^{\prime \prime}$. For example, if $E$ equals NB and $\Delta E$ equals PS, then $U$ equals NM.

Table 2. Fuzzy Control Rules Table.

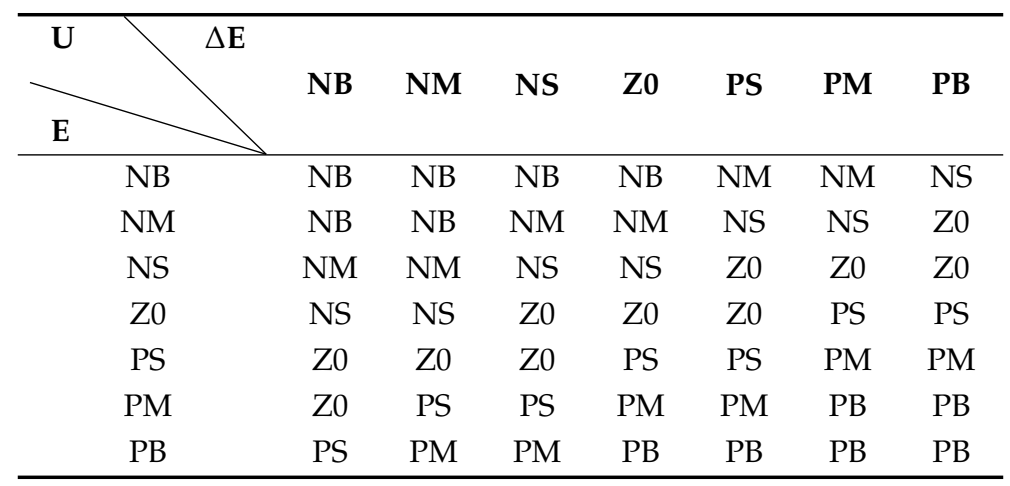

(3) Fuzzy reasoning and defuzzification

From the fuzzy control rule table in Table $2,7 \times 7=49$ rules are obtained. Each rule corresponded to a different power deviation, deviation change rate and language value of the control quantity. According to the membership function, the fuzzy set assignment table of power deviation $E$, deviation change rate $\Delta E$ and control quantity $U$ was then obtained, as shown in Table 3.

Table 3. Assignment Table of Fuzzy Sets A, B and C.

\begin{tabular}{cccccccc}
\hline & $\mathbf{- 3}$ & $\mathbf{- 2}$ & $\mathbf{- 1}$ & $\mathbf{0}$ & $\mathbf{1}$ & $\mathbf{2}$ & $\mathbf{3}$ \\
\hline $\mathrm{NB} A_{1}, B_{1}, C_{1}$ & 1 & 0.5 & 0 & 0 & 0 & 0 & 0 \\
$\mathrm{NM} A_{2}, B_{2}, C_{1}$ & 0 & 1 & 0.5 & 0 & 0 & 0 & 0 \\
$\mathrm{NS} A_{3}, B_{3}, C_{3}$ & 0 & 0.5 & 1 & 0.5 & 0 & 0 & 0 \\
$\mathrm{Z} 0 A_{4}, B_{4}, C_{4}$ & 0 & 0 & 0.5 & 1 & 0.5 & 0 & 0 \\
$\mathrm{PS} A_{5}, B_{5}, C_{5}$ & 0 & 0 & 0 & 0.5 & 1 & 0.5 & 0 \\
$\mathrm{PM} A_{6}, B_{6}, C_{6}$ & 0 & 0 & 0 & 0 & 0.5 & 1 & 0 \\
$\mathrm{~PB} A_{7}, B_{7}, C_{7}$ & 0 & 0 & 0 & 0 & 0 & 0.5 & 1 \\
\hline
\end{tabular}


The fuzzy subsets corresponding to each language value were $A_{1}-A_{7}, B_{1}-B_{7}$ and $C_{1}-C_{7}$. According to the membership function, the corresponding fuzzy subsets of each language value were $A_{i}, B_{j}$ and $C_{i j}$.

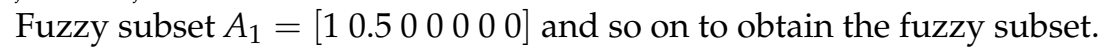

The fuzzy relational submatrix of fuzzy set $A$ was $R A_{i}=A_{i} * C_{i j}$ and the fuzzy relational submatrix of fuzzy set $B$ was $R B_{i}=B_{j} * C_{i j}(i=1,2, \ldots, 23, j=1,2, \ldots, 41)$.

According to this method, 23 and 41 relational sub-matrices could be obtained, respectively. We took the union of all sub-matrices to get the fuzzy relation matrix $R A=\cup R A_{i}$ and $R B=\cup R B_{j}$. The analog output can be obtained as:

$$
U=e \circ R A \cap \Delta e \circ R B
$$

The analog output obtained from Equation (3) was a $1 \times 7=7$ fuzzy vector. The row element $u\left(z_{i j}\right)$ of each row corresponded to the corresponding discrete variable $z_{j}$, which could be solved by the weighted average method formula.

The slope correction amount of the gangue frequency curve was:

$$
u=\frac{\sum_{j=1}^{49} u\left(z_{i j}\right) * z_{j}}{\sum_{j=1}^{49} u\left(z_{i j}\right)}(i=j=1,2, \ldots, 49) .
$$

\subsection{Fuzzy Logic Control Output}

The system detection device detected the field data in real-time and compared it with the given value. After A/D conversion, it was quantified into the basic domain variable and then the fuzzy language value $\mathrm{U}$ was the output from the look-up table and the fuzzy judgment obtained the clarity value $u$.

The change rule of gangue frequency was

$$
a=u \cdot \frac{b-a}{2 n}+\frac{a+b}{2} .
$$

According to fuzzy logic formula:

$$
f_{\mathrm{t}}=a \cdot P_{\mathrm{t}} \cdot \frac{45}{P_{\mathrm{h}}-P_{1}}+\frac{5 P_{\mathrm{h}}-50 P_{1}}{P_{\mathrm{h}}-P_{1}}
$$

The output was converted into a 4 20 mA DC signal by the D/A digital-analog device to the gangue motor frequency converter to control the motor speed.

\subsection{Design of the PLC Control System}

The electrical hardware system was mainly composed of a Panasonic FPX-C60R programmable controller, an industrial computer, a power transmitter and a frequency inverter. PLC was used as a fuzzy controller to receive the power transmitter signal, calculate the power error and the error rate of change for fuzzy processing. We then obtained the inverter control frequency $f_{\mathrm{t}}$ to control the speed of the gangue discharge motor. The industrial computer was based on KingView monitoring software for the equipment operation, parameter setting, data storage, real-time monitoring and other tasks. The control program block diagram is shown in Figure 9. 


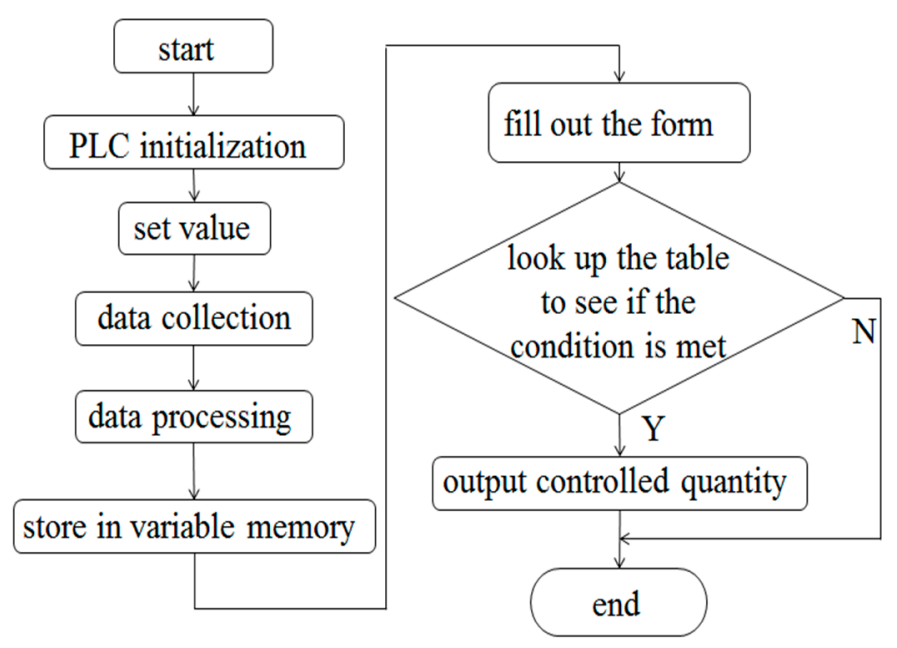

Figure 9. A block diagram of the control program.

\section{Analysis of the Industrial Experiment and Result}

The instability of the actual coal gangue feeding is the main factor affecting the gangue discharge effect. The power change of the driving motor of the moving sieve body reflects the change of the coal gangue in the moving sieve. When the gangue feed increases, the motor power will increase accordingly. The purpose of an automatic control is to quickly adjust the frequency of the gangue discharge motor to quickly restore the uneven change of the incoming gangue to the state when the jig bed was stabilized. In this experiment, manual intervention and adjustment of the system feed volume were used and King View software was used to monitor the power change of the driving motor of the moving sieve body and the output curve of the gangue motor frequency in real-time. According to the actual parameters of the moving sieve jig, the lower limit value was $35 \mathrm{~kW}$ and the upper limit value was $75 \mathrm{~kW}$. When the feeding rate was $280 \mathrm{t} / \mathrm{h}$, the system was stable. At this time, the actual power of the moving sieve motor was $55 \mathrm{~kW}$ and the gangue discharge frequency was $28 \mathrm{~Hz}$.

We adjusted the feeder to control the feed volume of the moving sieve jig as required and to get the power change of the motor and the output curve of the gangue discharge motor frequency as shown in Figure 10, Figure 11, and Figure 12. The curve shows the relationship between time (x axis) and power (y axis). The unit of power was $\mathrm{kW}$ and the unit of frequency was $\mathrm{Hz}$.

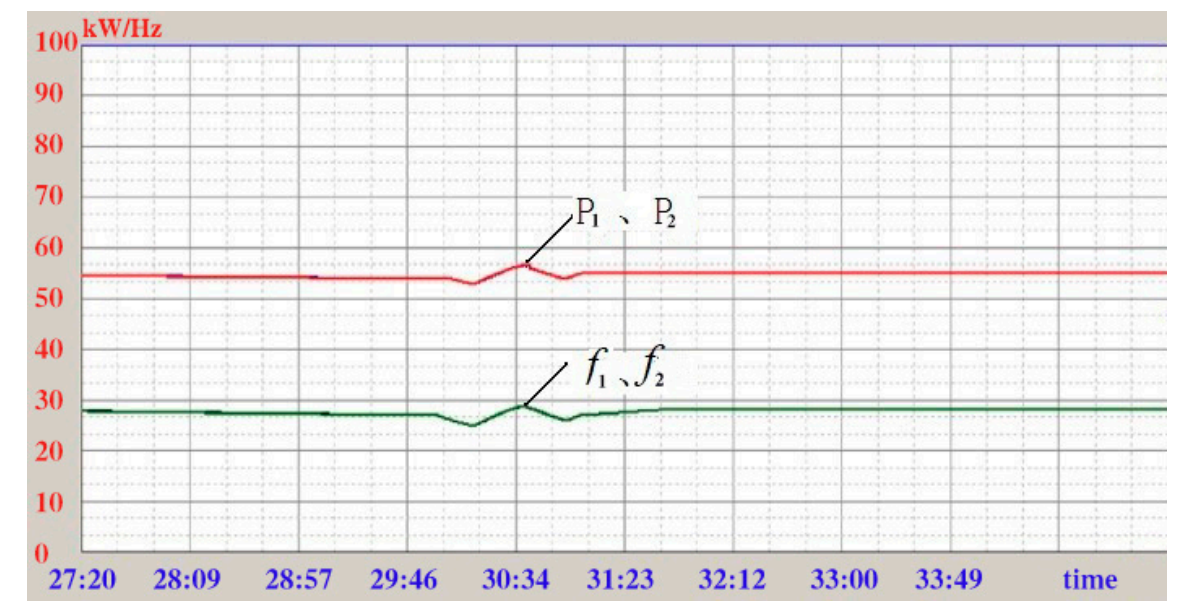

Figure 10. A small fluctuation of the incoming material. Fuzzy logic control: —- Power of moving sieve driving motor $P_{1}$, . Discharge frequency $f_{1}$, logical linear control: $\longrightarrow$. Power of moving sieve driving motor $P_{2}$, . Discharge frequency $f_{2}$. 


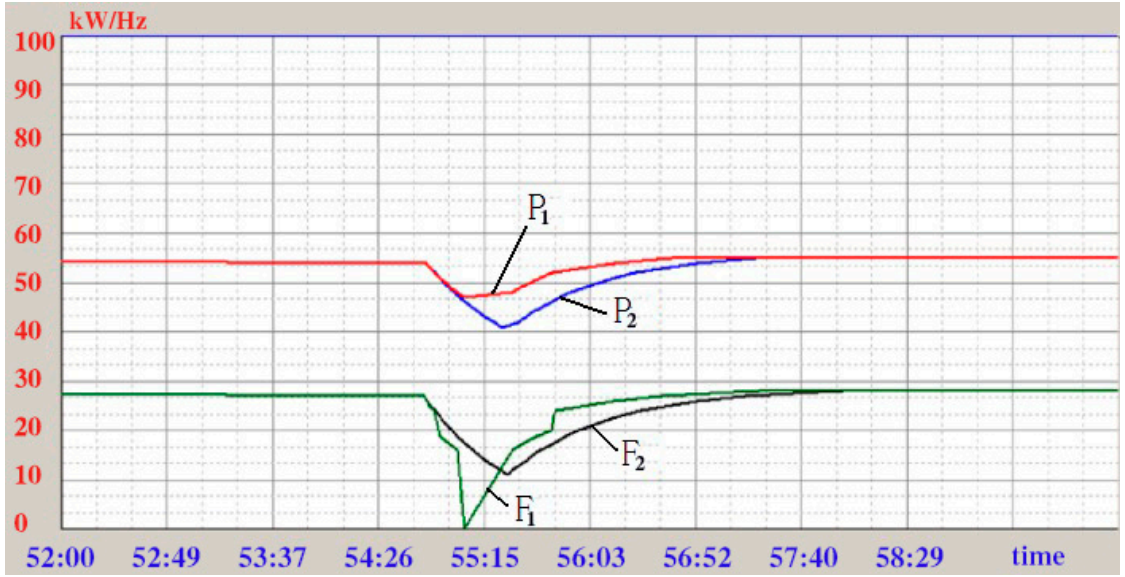

Figure 11. The change rule when there was no feeding. Fuzzy logic control: sieve drive motor $P_{1}$, . Discharge frequency $f_{1}$, logical linear control: Power of moving sieve driving motor $P_{2}$, Discharge frequency $f_{2}$.

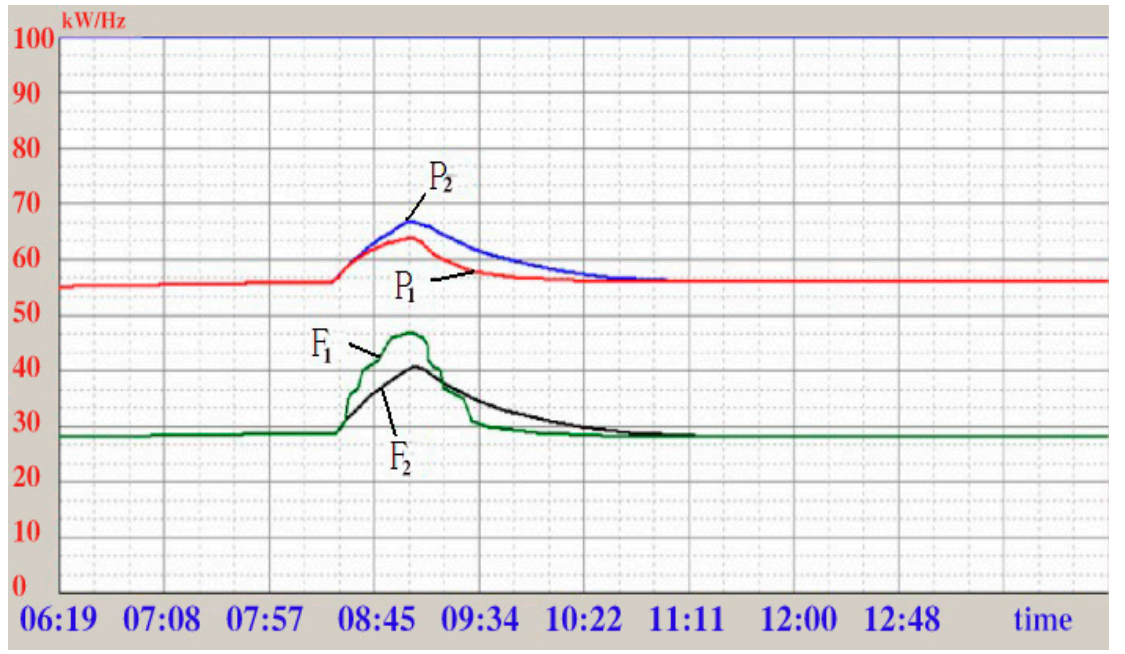

Figure 12. The change rule when the input quantity was $500 \mathrm{t} / \mathrm{h}$. Fuzzy logic control: — moving sieve driving motor $P_{1}$, —. Discharge frequency $f_{1}$, logical linear control: $\longrightarrow$. Power of moving sieve driving motor $P_{2}, \longrightarrow$. Discharge frequency $f_{2}$.

(1) When the gangue feeding quantity fluctuated in a small range, the curve shown in Figure 10 was obtained: The actual power of the moving sieve changed from $52 \mathrm{~kW}$ to $58 \mathrm{~kW}$ at 0:00 to 30:12 and recovered to $55 \mathrm{~kW}$ after 30:52. When the gangue feeding quantity fluctuated in a small range, the power $P_{1}$ and $P_{2}$ of the moving sieve drive motor in the two kinds of control fluctuated up and down the same and the frequency $f_{1}$ and $f_{2}$ of the waste discharge motor fluctuated the same. There was no difference in control effect and the curves were coincidental.

(2) When there was a 40 s non-feeding interval at the feeding end, the curve shown in Figure 11 was obtained.

When feeding stopped at 54:48, it could be seen that $f_{1}$ had a buffer decreasing frequency and then rapidly decreased until it was 0 , which meant less gangue discharge, while $f_{2}$ slowly decreased. $P_{1}$ decreased less than $P_{2}$; when $f_{1}$ was $0, P_{1}$ stopped falling. The gangue layer remained stable.

The feed volume recovered at 55:28 and $f_{1}$ and $P_{1}$ returned to stability at 56:03. The adjustment time was $40 \mathrm{~s}$. However, $f_{2}$ and $P_{2}$ tended to be stable at 57:10 and the adjustment time was $102 \mathrm{~s}$. It could be seen that fuzzy logic control recovered and stabilized faster than logic linear control. 
(3) When the gangue feeding quantity at the feeding end was $500 \mathrm{t} / \mathrm{h}$ and lasted for $40 \mathrm{~s}$, the obtained curve is shown in Figure 12. The feed volume started to increase at 08:25. It could be seen that $f_{1}$ had a buffer rising frequency and then rose rapidly. When we increased the gangue displacement, $f_{2}$ rose slowly. The increase of $\mathrm{P}_{1}$ was less than that of $\mathrm{P}_{2}$ and the gangue layer was more stable, avoiding damage to the gangue layer structure.

The feed volume recovered at 09:05, $f_{1}, \mathrm{P}_{1}$ stabilized at 09:34 and the adjustment time was $29 \mathrm{~s}$. However, $f_{2}$ and $P_{2}$ stabilized at 10:38 and the adjustment time was $93 \mathrm{~s}$. It could be seen that fuzzy logic control recovered and stabilized faster than logic linear control.

From the above industrial test results, it could be seen that the fuzzy logic control system could well solve the problem of the non-linear, time-varying and hysteresis mathematical model of the coal washing process with a moving sieve jig. The control system had good control stability and could achieve the expected goal.

\section{Conclusions}

(1) A primary coal preparation system based on a mechanical moving sieve jig machine was proposed and a gangue discharge process suitable for the underground coal mine environment was designed. The structural innovative design of the jig machine improved the screening efficiency and met the needs of the special space in an underground coal mine.

(2) Aiming at the non-linear, time-varying uncertainty and pure lag characteristics of the gangue discharge control system of the underground moving sieve jig, a fuzzy logic combination control method was proposed. The input and output parameters of the system were fuzzy processed to realize the discharge fuzzy logic control of gangue motor speed.

(3) Industrial experiments obtained the variation law of gangue quantity in the moving sieve and the output curve of the gangue motor frequency under three working conditions. The results showed that under the fuzzy logic control system, when the feed material fluctuated suddenly or greatly, the jig bed in the moving sieve could quickly stabilize. The separation efficiency of the coal gangue has been greatly improved and the ideal gangue discharging effect was achieved. It can effectively solve the problems of non-linearity, time-variation and difficulty in determining the hysteresis mathematical model of the moving sieve jigging coal washing process and achieved the expected gangue discharge target.

Author Contributions: D.S. was responsible for the overall scheme determination and manuscript writing. Z.Y. was responsible for the optimization design of equipment. J.W. was responsible for the experimental implementation. Y.W. and Y.L. were responsible for the article editing. All authors have read and agreed to the published version of the manuscript.

Funding: This research was funded by the Fundamental Research Funds for the Central Universities (No: 2019YJ02).

Conflicts of Interest: The authors declare no conflict of interest.

\section{Appendix A}

Table A1. The Technical Term and Function for Figure 1.

\begin{tabular}{cr}
\hline Technical Term & Function \\
\hline Raw coal screen & Also named roller screen, a screen grain diameter greater than $50 \mathrm{~mm}$ of coal and gangue \\
\hline Moving sieve jig & Sieving coal and gangue, which is the main research object of this paper \\
\hline Fixed screen & The last screen to separate the coal and gangue \\
\hline Sedimentation tank & Sediments the coal slime \\
\hline High frequency screen & Separates the coal slime and water by high frequency vibration \\
\hline Filter press & Dehydrates the coal slime \\
\hline Recycling pool & Provides water for the moving sieve jig \\
\hline
\end{tabular}




\section{References}

1. Cao, J.J.; Liu, Y.J.; Guo, G.L. The current situation in comprehensive utilization of gangue. Chin. J. Environ. Eng. 2004, 5, 19-22.

2. Ma, L.Q.; Li, Y.S. The clean production technology of replacement of coal gangue in coal mine. J. China Coal Soc. 2010, 35, 816-819.

3. Miao, X.X.; Zhang, J.X. Key technologies of integration of coal mining-gangue washing-backfilling and coal mining. J. China Coal Soc. 2014, 39, 1424-1433.

4. Zhang, Q.; Zhang, J.X.; Wu, Z.Y. Overview of Solid Backfilling Technology Based on Coal-Waste Underground Separation in China. Sustainability 2019, 11, 2118. [CrossRef]

5. Wang, X.M.; Zhao, B.; Zhang, C.S.; Zhang, Q.L. Paste-like self-flowing transportation backfilling technology based on coal gangue. Min. Sci. Technol. 2009, 19, 137-143. [CrossRef]

6. Fu, Z.Y.; Liu, Y.M.; Liu, J. The research and application of underground coal and gangue separation technology in the field of energy conservation in Xinwen Mining area. Sci. Technol. Inf. 2011, 27, 758-808.

7. Ding, K.J.; Janusz, S.L. Coal reverse flotation. Part I: Separation of a mixture of subbituminous coal and gangue minerals. Miner. Eng. 2005, 19, 72-78. [CrossRef]

8. Liu, L.P.; Ren, J.J.; Liu, J. General Design of Downhole Moving Screen Discharging Gangue Machine. Coal Mine Mach. 2013, 34, 36-38.

9. Zhou, J.W.; Wang, F.R.; Liu, Y.; Du, C.L. Theoretical and experimental research on ballistic separation for coal and gangue underground. J. Cent. South Univ. 2015, 46, 498-504.

10. Li, J.P.; Yang, D.L.; Du, C.L. Evaluation of an Underground Separation Device of Coal and Gangue. Int. J. Coal Prep. Utili. 2013, 33, 188-193. [CrossRef]

11. Zheng, K.H.; Du, C.L.; Li, J.P. Underground pneumatic separation of coal and gangue with large size $(\geq 50$ $\mathrm{mm}$ ) in green mining based on the machine vision system. Powder Technol. 2015, 278, 223-233. [CrossRef]

12. Wang, W.D.; Zhang, C. Separating coal and gangue using three-dimensional laser scanning. Int. J. Miner. Process. 2017, 169, 79-84. [CrossRef]

13. Zhang, R.Z.; Fu, X.H.; Wei, L.B.; Xu, Z.Q. Fluid kinetics study on jig washer bed dilation and stratification. J. China Coal Soc. 2003, 28, 193-198.

14. Mukherjee, A.K.; Dwivedi, V.K.; Mishra, B.K. Analysis of a laboratory jigging system for improved performance. Miner Eng. 2005, 18, 1037-1044. [CrossRef]

15. Lv, T.T.; Ma, X.P.; Chen, L. Simulation of PID control of jig discharging system optimized by genetic algorithm. Ind. Mine Autom. 2013, 39, 67-70.

16. Liu, H.S. Products separation of air pulse jig and its discharging device. Min. Process Equip. 2000, 01, 41-44.

17. Kumar, S.; Venugopal, R. Performance analysis of jig for coal cleaning using 3D response surface methodology. Int. J. Min Sci. Technol. 2017, 27, 333-337. [CrossRef]

18. Sanders, G.J.; Ziaja, D.; Kottmann, J. Cost-Efficient Beneficiation of Coal by ROMJIGs and BATAC Jigs. Int. J. Coal Prep. Util. 2002, 22, 395-400.

19. Zhu, J.B.; Cao, Y.L.; Li, X.G.; Jia, C.L.; Chen, Q.R. Ascertainment of Index es for Jigging Separation and Its Optimum Operation by Using Artificial Neural Network. J. China Univ. Min. Technol. 1999, 2, 47-50.

20. Ma, F.Q.; Ding, E.J.; Jin, L.; Tan, D.J. Intelligent Control for Jigging Process. J. China Univ. Min. Technol. 2002, 3, 80-84.

21. Ni, J.J.; Sun, W.; Li, M. Research and Application of On-line Clean Ash Feedback Control System of Jigging Machine. Coal Prep. Technol. 2003, 6, 112-114.

22. Yang, J.M. Intelligent Control Method of Coal Jigging Process. Master's Thesis, Taiyuan University of Technology, Taiyuan, China, March 2004.

23. Cao, W. Mechanism Optimization and Control Method Research of Moving Sieve Jig for Underground Coal Mine Raw Coal Preparation System. Master's Thesis, China University of Mining and Technology, Beijing, China, 2019.

24. Gang, F. A Survey on Analysis and Design of Model-Based Fuzzy Control Systems. IEEE Trans. Fuzzy Syst. 2006, 14, 676-697.

25. King, P.J.; Mamdani, E.H. The application of fuzzy control systems to industrial processes. Automatica 1977, 13, 235-242. [CrossRef]

26. Sugeno, M. An introductory survey of fuzzy control. Inf. Sci. 1985, 36, 59-83. [CrossRef] 
27. Bogdan, S.; Kovacic, Z. Fuzzy Controller Design: Theory and Applications; CRC/Taylor \& Francis: Boca Raton, FL, USA, 2006.

28. Hellendoorn, H.; Palm, R. Fuzzy system technologies at Siemens R \& D. Fuzzy Set Syst. 1994, 63, $245-269$.

29. Radu-Emil, P.; Hans, H. A survey on industrial applications of fuzzy control. Comput. Ind. 2011, 62, $213-226$.

Publisher's Note: MDPI stays neutral with regard to jurisdictional claims in published maps and institutional affiliations.

(C) 2020 by the authors. Licensee MDPI, Basel, Switzerland. This article is an open access article distributed under the terms and conditions of the Creative Commons Attribution (CC BY) license (http://creativecommons.org/licenses/by/4.0/). 